\title{
EVALUASI KINERJA JALAN TERHADAP RENCANA PEMBANGUNAN JALAN DUA JALUR
}

\author{
Said Jalalul Akbar ${ }^{1)}$, Wesli $^{2)}$, Burhanuddin ${ }^{3)}$, Muammar Khadafi ${ }^{4)}$ \\ Jurusan Teknik Sipil, Fakultas Teknik, Universitas Malikussaleh \\ email: jaakidani@gmail.com ${ }^{l}$, wesli@unimal.ac.id ${ }^{2)}$
}

\begin{abstract}
Abstrak
Jalan Banda Aceh-Medan Simpang Jalan Elak-Jembatan Alue Awe saat ini sangat padat arus lalulintas yang melintasi. Hal ini disebabkan beberapa faktor diantaranya adalah pada lokasi tersebut telah didirikan beberapa gedung/bangunan penting sebagai fasilitas umum seperti Sekolah Tinggi Agama Islam Negeri, Rumah Sakit Umum kota Lhokseumawe, Politeknik Negeri dan pertokoan serta tempat-tempat usaha lainnya milik masyarakat. Penelitian ini bertujuan ingin mengetahui apakah jalan tersebut masih mampu melayani lalulintas sehubungan dengan kondisi pada lokasi tersebut. Penelitian ini menggunakan metode MKJI 1997. Dari hasil penelitian diperoleh bahwa nilai LHR pada hari Rabu 930,71 smp/jam, hari Kamis $865 \mathrm{smp} / \mathrm{jam}$ dan hari Minggu $578,02 \mathrm{smp} / \mathrm{jam}$. Nilai derajat kejenuhan rata-rata 0,44 dan tingkat pelayanan termasuk pada katagori C yang bermakna bahwa Sp. Jalan Elak-Jembatan Alue Awe arus lalulintasnya masih stabil dan kecepatan makin terbatas. Hasil pengamatan langsug di lapangan mendekati dengan hasil penelitian yang berarti rencana pembangunan jalan dua jalur dua arah sudak layak untuk dilaksanakan.
\end{abstract}

Kata kunci: Kapasitas, Tingkat pelayanan, Kinerja jalan

\section{Pendahuluan}

Transportasi merupakan salah satu hal yang sangat dibutuhkan dalam kegiatan perekonomian. Kegiatan transportasi memerlukan sarana seperti kenderaan bermotor maupun tidak bermotor dan prasarana berupa jalan. Dengan adanya kegiatan transportasi maka terjadilah pergerakan arus lalu-lintas. Padatnya angkutan jalan khususnya di daerah perkotaan yang diakibatkan oleh perkembangan teknologi, bertambahnya jumlah penduduk dan kebutuhan akan sarana transportasi menyebabkan bertambahnya kebutuhan akan ruang untuk prasarana lalu-lintas seperti jalan, lokasi parkir dan lain-lain.

Pengamatan langsung dilapangan secara kasat mata bahwa kondisi Jalan Banda Aceh-Medan khususnya dari simpang Jalan Elak sampai dengan Jembatan Alue Awe saat ini sangatlah padat dengan arus lalulintas yang melintasi pada jalan tersebut. Hal ini disebabkan oleh beberapa factor diantaranya adalah pada lokasi tersebut telah didirikan beberapa gedung-gedung/bangunan penting pusat kegiatan masyarakat Seperti Sekolah tinggi Agama Islam Negeri (STAIN), Rumah Sakit Umum (RSU) kota Lhokseumawe, Politeknik Negeri lhokseumawe dan pertokoan serta tempat-tempat usaha lainnya milik masyarakat. Dengan adanya bangunanbangunan tersebut tentunya setiap hari banyak masyarakat yang berdatangan pada lokasi tersebut sesuai kegiatan masing-masing. Sehingga lalulintas pada jalan tersebut menjadi padat dan terasa sedikit macet.

Pertumbuhan ekonomi menyebabkan mobilitas seseorang meningkat melebihi sistem prasarana transportasi yang ada. Kurangnya investasi pada suatu sistem jaringan transportasi dalam waktu yang cukup lama dapat mengakibatkan 
sistem prasarana transportasi tersebut menjadi sangat rentan terhadap terjadinya lalulintas. Hal ini terjadi karena volume arus lalulintas meningkat melebihi kapasitas jalan yang ada (Wesli, 2012)

Berdasarkan parmasalahan di atas perlu kiranya dilakukan penelitian dengan tujuan penelitian adalah ingin mengetahui kinerja jalan Banda Aceh-Medan dari Sp. Jalan Elak sampai dengan Jembatan Alue Awe apakah masih mampu melayani/menampung arus lalulintas yang melintasi dan apakah sudah layak dengan rencana pemeritah ingin membuat jalan dua jalur. Penelitian ini dilakukan dengan memakai metode MKJI (Manual Kapasitas Jalan Indonesia 1997).

\section{Tinjauan Kepustakaan}

Kapasitas Jalan mendefinisikan ruas jalan perkotaan sebagai ruas jalan yang memiliki pengembangan permanen dan menerus sepanjang seluruh atau hampir seluruh jalan. Adanya jam puncak lalu-lintas pagi, siang dan sore serta tingginya kenderaan juga merupakan ciri prasarana lalu-lintas perkotaan. Jalan perkotaan juga diwarnai ciri alinyemen vertikal yang datar atau hampir datar serta alinyemen horizontal yang lurus atau hampir lurus seluruh jalan. Adanya jam puncak lalulintas pagi, siang dan sore serta tingginya persentase kenderaan pribadi juga merupakan ciri lalu-lintas perkotaan. Keberadaan kerb juga merupakan ciri prasarana jalan perkotaan (MKJI, 1997).

Menurut Sukirman (1999), mengemukakan bahwa volume lalu-lintas menunjukkan jumlah kenderaan yang melintasi suatu titik pengamatan dalam satu satuan waktu (menit, jam, hari). Volume lalu-lintas yang diperoleh dari hasil penelitian kemudian dikonversikan kedalam satuan mobil penumpang (smp), untuk kenderaan berat dikalikan 1,3, kenderaan ringan dikalikan dengan 1,0, sepeda motor dikalikan dengan 0,2 sedangkan untuk becak motor dikalikan dengan 0,2 sama seperti dengan sepeda motor. Persamaam yang digunakan untuk menentukan volume lalu-lintas dapat dilihat pada rumus 1 .

$$
L H R=\frac{N}{T}
$$

Keterangan:

LHR = Lalu-lintas harian rata-rata $(\mathrm{smp} / \mathrm{jam})$

$\mathrm{N}=$ Volume lalu-lintas selama pengamatan ( $\mathrm{smp}$ )

$\mathrm{T}=$ Lamanya pengamatan (jam)

Ekivalen mobil penumpang (emp) adalah faktor konversi berbagai jenis kenderaan dibandingkan dengan mobil penumpang sehubungan dengan dampaknya pada pergerakan lalu-lintas. Faktor emp dapat dilihat pada tabel dibawah ini. Pengelompokan kenderaan berdasarkan Manual Kapasitas Jalan Indonesia (1997) adalah sebagai berikut:

1. Kenderaan ringan atau Light Vehicle (LV) yaitu kenderaan bermotor dua as beroda 4 dengan jarak as 2,0 sampai 3,0 meter (termasuk mobil penumpang, opelet, mikrobis, pick-up dan truck kecil sesuai dengan klasifikasi Bina Marga)

2. Kenderaan berat atau Heavy Vehicle (HV) yaitu kenderaan bermotor dengan jarak as lebih dari 3,5 meter, biasanya beroda lebih dari 4 (termasuk bis, truck 2 
as, truck 3 as dan truck kombinasi sesuai dengan sistem klaasifikasi Bina Marga).

3. Sepeda motor atau Motor Cycle (MC) yaitu kenderaan bermotor beroda dua atau tiga (termasuk sepeda motor dan kenderaan beroda 3 sesuai dengan klasifikasi Bina Marga).

Tabel 1 Ekivalensi Mobil Penumpang (emp)

\begin{tabular}{|l|l|c|}
\hline No & \multicolumn{1}{|c|}{ Tipe Kenderaan } & EMP \\
\hline 1 & Kenderaan ringan (LV) & 1,0 \\
2 & Kenderaan berat (HV) & 1,3 \\
3 & Sepeda motor (MC) & 0,2 \\
\hline
\end{tabular}

Sumber: MKJI (1997)

Menurut Sukirman (1999), Lalu-lintas Harian Rara-rata adalah volume lalulintas rata-rata dalam satu hari. Dari cara memperoleh data tersebut dikenal 2 jenis lalu-lintas harian rata-rata, yaitu lalu-lintas harian rata-rata tahunan (LHRT) dan lalu-lintas harian rata-rata (LHR). LHRT adalah jumlah lalu-lintas kenderaan ratarata yang melewati satu jalur selama 24 jam dan diperoleh dari data selama satu tahun penuh.

$$
\text { LHRT }=\frac{\text { Jumlah }}{365}
$$

LHRT dinyatakan dalam smp/hari/2 arah atau kenderaan/hari/2 arah untuk jalan 2 jalur 2 arah, smp/hari/1 arah atau kenderaan/hari/1 arah untuk jalan berlajur banyak dengan median.

Menurut Sukirman (1999), Kapasitas adalah jumlah kenderaan maksimum yang dapat melewati suatu penampang jalan pada jalur jalan selama 1 jam dengan kondisi serta arus lalu-lintas tertentu. Menurut Manual Kapsitas Jalan Indonesia (1997), kapasitas adalah arus lalu-lintas maksimum yang dapat dipertahankan pada kondisi tertentu. Untuk jalan dua jalur, kapasitas ditentukan untuk arus dua arah. Tetapi untuk jalan dua jalur dengan banyak lajur, arus dipisahkan per arah dan kapasitas ditentukan per lajur. Persamaan yang digunakan untuk menentukan kapasitas dapat dilihat pada rumus 3 .

$$
C=C_{o} x F C_{w} \times F C_{S P} x F C_{S F} x F C c s
$$

di mana:

$\mathrm{C} \quad=$ Kapasitas ( $\mathrm{smp} / \mathrm{jam})$

Co = Kapasitas Dasar (smp/jam)

$\mathrm{FCw}=$ Faktor penyesuaian kapasitas akibat lebar jalur lalu lintas

FCsp = Faktor penyesuaian kapasitas akibat pemisahan arah

FCsf = Faktor Penyesuaian kapasitas akibat hambatan samping

FCcs $=$ Faktor Penyesuaian kapasitas akibat ukuran kota

Evaluasi Kinerja Jalan Terhadap Rencana Pembangunan Jalan Dua Jalur - Said Jalalul Akbar, Wesli, Burhanuddin, Muammar Khadafi 
Tabel 2 Kapasitas Dasar (Co) Jalan Perkotaan

\begin{tabular}{|l|c|}
\hline \multicolumn{1}{|c|}{ Tipe Jalan } & $\begin{array}{c}\text { Kapasitas Dasar } \\
\text { (smp/jam) }\end{array}$ \\
\hline Dua lajur tak terbagi & 2900 \\
\hline Empat lajur tak terbagi & 1500 \\
\hline Empat lajur terbagi atau jalan satu arah & 1650 \\
\hline
\end{tabular}

Sumber: MKJI (1997)

Menurut Anonim (1997), derajat kejenuhan adalah perbandingan dari volume lalu-lintas terhadap kapasitasnya. Gambaran ini menunjukkan suatu ruas jalan mempunyai masalah atau tidak, berdasarkan asumsi jika volume lalu-lintas makin dekat dengan kapasitanya kemudahan bergerak makin terbatas. Persamaan yang digunakan untuk menentukan derajat kejenuhan dapat dilihat pada rumus 4

$$
D S=\frac{Q}{C}
$$

Keterangan:

$$
\begin{array}{ll}
\mathrm{DS} & =\text { Derajat kejenuhan } \\
\mathrm{Q} & =\text { Volume lalu-lintas (smp/jam) } \\
\mathrm{C} & =\text { Kapasitas (smp/jam) }
\end{array}
$$

Tabel.3 Hubungan tingkat pelayanan dengan derajat kejenuhan

\begin{tabular}{|c|c|c|}
\hline $\begin{array}{c}\text { Tingkat Pelayanan } \\
\text { (LOS) }\end{array}$ & $\begin{array}{c}\text { Derajat Kejenuhan } \\
\text { (DS) }\end{array}$ & Keterangan \\
\hline A & $0-0,2$ & $\begin{array}{c}\text { Arus bebas, kecepatan } \\
\text { bebas }\end{array}$ \\
\hline B & $0,2-0,4$ & $\begin{array}{c}\text { Arus stabil, kecepatan } \\
\text { mulai terbatas }\end{array}$ \\
\hline C & $0,4-0,6$ & $\begin{array}{c}\text { Arus stabil, kecepatan } \\
\text { makin terbatas }\end{array}$ \\
\hline D & $0,6-0,8$ & $\begin{array}{c}\text { Arus mulai tidak stabil, } \\
\text { kecepatan menurun }\end{array}$ \\
\hline E & $0,8-1,0$ & $\begin{array}{c}\text { Arus tidak stabil, } \\
\text { kecepatan rendah }\end{array}$ \\
\hline F & $\geq 1,0$ & $\begin{array}{c}\text { Arus terhambat, } \\
\text { kecepatan rendah }\end{array}$ \\
\hline
\end{tabular}

Sumber: MKJI (1997)

Kecepatan arus bebas (FV) didefinisikan sebagai kecepatan pada tingkat arus nol, yaitu kecepatan yang akan dipilih pengemudi jika mengendarai kenderaan bermotor tanpa dipengaruhi oleh kenderaan bermotor lain di jalan (MKJI, 1997). Kecepatan arus bebas kenderaan ringan telah dipilih sebagai kriteria dasar untuk kinerja jalan pada arus $=0$. Kecepatan arus bebas untuk kenderaan berat dan sepeda motor juga diberikan sebagai referensi. Kecepatan arus bebas untuk mobil penumpang biasanya 10-15\% lebih tinggi dari tipe kenderaan ringan lain. Persamaan yang digunakan untuk menentukan kecepatan arus bebas dapat dilihat pada rumus 5

Evaluasi Kinerja Jalan Terhadap Rencana Pembangunan Jalan Dua Jalur - Said Jalalul Akbar, Wesli, Burhanuddin, Muammar Khadafi 
$F V \quad=\left(F V_{o}+F V w\right) x F F V_{s f} x F F c s$

di mana:

$\mathrm{FV} \quad=$ Kecepatan arus bebas kenderaan ringan $(\mathrm{km} / \mathrm{jam})$

$\mathrm{FVo}=$ Kecepatan arus bebas dasar kenderaan ringan $(\mathrm{km} / \mathrm{jam})$

$\mathrm{FVw}=$ Faktor penyesuaian akibat lebar jalan $(\mathrm{km} / \mathrm{jam})$

FFVsf = Faktor Penyesuaian akibat hambatan samping

FVcs $=$ Faktor Penyesuaian kapasitas akibat ukuran kota

\section{Metode Penelitian}

Tahapan dalam pelaksanaan penelitian meliputi identifikasi masalah, studi literatur, pengumpulan data berupa data primer dan data sekunder dan melakukan pengolahan data untuk mendapatkan hasil penelitian. Data primer adalah data yang diperoleh langsung dari hasil penelitian di lapangan berupa kondisi geometrik jalan, kecepatan dan hambatan samping sedangkan data sekunder adalah berupa peta wilayah yang dijadikan objek penelitian. Kondisi geometrik Jalan Banda Aceh-Medan Sp. Jalan Elak-Jembatan Alue Awe pada saat penelitian adalah tipe 1 Jalur 2 lajur dan 2 arah tak terbagi (tipe 2/2 UD) dengan lebar efektif jalur lalu-lintas $6,00 \mathrm{~m}$. Bahu jalan dengan perkerasan, dengan aktifitas samping jalan yang padat. Untuk lebar bahu bagian timur 1,0 $\mathrm{m}$ dan bagian barat 1,0 m (data geometrik ruas jalan tersebut dapat dilihat pada gambar 3.2. Data geometrik jalan tersebut diperoleh langsung dari hasil pengukuran di lokasi penelitian

Untuk data volume arus lalu-lintas diperoleh dengan cara mengumpulkan data pengguna jalan (arus lalu-lintas) pada setiap jam dalam satu hari pada jalan Banda Aceh-Medan Sp. Jalan Elak s/d Jembatan Alue Awe selama 11 jam perhari. Tujuan dari pengumpulan data ini untuk mendapatkan gambaran mengenai jenis kenderaan, arah serta volume lalu-lintas yang melewati garis melintang penampang jalan tersebut dari 2 arah. yang nantinya akan dipergunakan sebagai data primer dalam penelitian ini. Pengumpulan data dari pangguna jalan pada setiap jam akan dilakukan dari pukul 07.00 wib pagi hingga pukul 18.00 wib sore pada jalan tersebut serta akan dicatat gangguan yang ada disekitar jalan yang ditinjau. Dari jenis-jenis kenderaan tersebut kemudian kami mengelompokkan menjadi 3 kelompok kenderaan berdasarkan jumlah roda atau as rodanya serta ukuran kenderaan. Dalam pengumpulan data ini melibatkan jumlah personil sebanyak 3 orang, dengan lama pengamatan selama tiga hari. Pengamatan volume lalu-lintas diperoleh dengan mencatat langsung jumlah kendaraan dan arah gerakannya yang lewat secara manual dengan membedakan atas jenis dan arah tujuannya.

Hambatan samping yang dicatat adalah berapa banyak jumlah dan jenis aktivitas samping jalan yang terjadi selama satu hari penuh dari jam 07.00 sampai 18.00 wib yang terjadi disepanjang jalan Banda Aceh-M Sp. Jalan Elak Jembatan Alue Awe seperti pejalan kaki, parker, kenderaan berhenti, kenderaan lambat serta kenderaan masuk/keluar untuk setiap jarak $200 \mathrm{~m}$ per jam. Kelas hambatan samping terdiri dari sangat rendah (VL), rendah (L), sedang $(\mathrm{M})$, tinggi (H) serta sangat tinggi ( $\mathrm{VH})$. 
Setelah dilakukan penelitian dan pengamatan di lapangan maka dilakukan pengolahan data dan analisa pengolahan data untuk mendapatkan hasil dari penelitian ini. Penelitian arus lalu-lintas akan menghasilkan seberapa banyak pengguna jalan dan kemacetan yang timbul akibat bertambahnya pengguna kendaraan bermotor maupun tidak bermotor. Besar atau kecilnya jumlah pengguna jalan yang dihitung per jam kemudian dijumlahkan sehingga diperoleh rekapitulasi jumlah pengguna jalan yang dari pukul 07.00 WIB pagi hingga pukul 18.00 WIB sore selama empat hari. Data tersebut belum dapat dipergunakan karena terdiri dari berbagai jenis kenderaan seperti sepeda motor, kenderaan ringan dan kenderaan berat, maka harus disetarakan atau dikonversi terlebih dahulu kedalam satuan yang sama yaitu satuan mobil penumpang (smp), sehingga nantinya akan didapat volume total kenderaan yang melewati jalan tersebut perhari. Maka dari hasil itu akan menghasilkan volume jam puncak dan volume rata-rata lalu-lintas jalan tersebut. Kemudian nilai volume lalu-lintas (Q), kelas hambatan samping, kecepatan arus bebas dan nilai kapasitas (C) diperoleh langkah selanjtnya adalah menghitung derajat kejenuhan (DS) dengan menggunakan rumus 2.4, maka akan didapat derajat kejenuhan untuk setiap hari pengamatan selama 4 hari, kemudian diambil nilai rata-rata dari derajat kejenuhan tersebut. Nilai dari derajat kejenuhan tersebut akan menggambarkan tingkat pelayanan (LOS) sehingga akan diketahui Jalan Banda Aceh- Medan Sp. Jalan Elak-Jembatan Alue Awe tersebut termasuk dalam katagori A, B, C, D, E atau F.

\section{Hasil dan Pembahasan}

Untuk mendapatkan nilai arus lalu-lintas (volume lalu-lintas) pada ruas jalan, terlebih dahulu dipilah-pilah sehingga dapat mengelompokkan jalur dan tipe kenderaan. Dari sini dapat diketahui jumlah tipe kenderaan pada tiap jalur.

Berdasarkan hasil penelitian di lapangan selama 3 hari, diperoleh besarnya volume lalu-lintas pada hari Rabu adalah 21466 kend/hari, pada hari Kamis volume lalu-lintasnya adalah $15533 \mathrm{kend} / \mathrm{hari}$, dan pada hari Minggu volume lalulintasnya $10984 \mathrm{kend} / \mathrm{hari}$. Setelah dikalikan dengan faktor emp (eqivalen mobil penumpang) untuk tiap jenis kenderaan maka nilai besaran Q atau Lalu-lintas Harian Rata-rata (LHR) berubah menjadi adalah sebagai berikut.

Tabel 4 Rekapitulasi LHR pada titik pengamatan masing-masing hari

\begin{tabular}{|l|c|c|c|}
\hline Hari & $\begin{array}{c}\mathbf{N} \\
\text { (smp/hari) }\end{array}$ & $\begin{array}{c}\text { T } \\
(\mathbf{j a m})\end{array}$ & $\begin{array}{c}\text { LHR } \\
\text { (smp/jam) }\end{array}$ \\
\hline Rabu & 10237,8 & 11 & 930,71 \\
Kamis & 9514,9 & 11 & 865 \\
Minggu & 6358,2 & 11 & 578,02 \\
\hline
\end{tabular}

Berdasarkan dari hasil pengamatan di lapangan, nilai kapasitas untuk Sp. Jalan Elak-Jembatan Alue Awe yang memiliki lebar efektif sebesar 6 meter dapat ditentukan berdasarkan rumus 3, adalah 2061,29 smp/jam. Hasil dari perhitungan hambatan samping yang didapatkan berdasarkan penelitian selama 3 hari pada Sp. Jalan Elak-Jembatan Alue Awe seperti ditunjukkan pada Table 5 sebagai berikut:

Evaluasi Kinerja Jalan Terhadap Rencana Pembangunan Jalan Dua Jalur - Said Jalalul Akbar, Wesli, Burhanuddin, Muammar Khadafi 
Tabel 5 Frekwensi Bobot Hambatan samping pada masing-masing hari

\begin{tabular}{|l|c|c|c|}
\hline $\begin{array}{c}\text { Tipe kejadian hambatan } \\
\text { samping }\end{array}$ & $\begin{array}{c}\text { Faktor } \\
\text { Bobot }\end{array}$ & $\begin{array}{c}\text { Frekwuensi } \\
\text { Kejadian }\end{array}$ & $\begin{array}{c}\text { Frekuensi } \\
\text { Bobot }\end{array}$ \\
\hline Pejalan kaki & 0,6 & $15,54 /$ jam $/ 150 \mathrm{~m}$ & 9,32 \\
Parkir, kenderaan berhenti & 0,8 & $26 /$ jam/150 m & 20,8 \\
Kenderaan lambat & 0,4 & $23,45 /$ jam & 9,38 \\
Kenderaan masuk \& keluar & 1,0 & $29,09 /$ jam $/ 150 \mathrm{~m}$ & 29,09 \\
\hline & & $\mathbf{9 3 , 9 9}$ & $\mathbf{6 8 , 5 9}$ \\
\hline
\end{tabular}

Hasil dari perhitungan kecepatan arus bebas yang didapatkan berdasarkan penelitian selama 3 hari pada Sp.Jalan Elak-Jembatan Alue Awe dapat ditentukan berdasarkan rumus 5 adalah $36 \mathrm{~km} / \mathrm{jam}$. Hasil dari perhitungan derajat kejenuhan yang didapatkan berdasarkan penelitian selama 3 hari pada Sp .Jalan ElakJembatan Alue Awe dengan menggunakan rumus (4) seperti ditunjukkan pada Table 6 sebagai berikut:

Tabel 6 Rekapitulasi kapasitas dan derajat kejenuhan

\begin{tabular}{|l|l|l|l|}
\hline Hari & \multicolumn{1}{|c|}{$\begin{array}{c}\text { Q } \\
\text { (LHR) }\end{array}$} & $\begin{array}{c}\text { C } \\
\text { (Kapasitas) }\end{array}$ & $\begin{array}{c}\text { DS } \\
\text { (Derajat kejenuhan) }\end{array}$ \\
\hline Rabu & 930,71 & & 0,45 \\
Kamis & 865 & 2061,29 & 0,42 \\
Minggu & 578,02 & & 0,28 \\
\hline
\end{tabular}

Dari hasil survey volume lalu-lintas yang dilakukan selama 3 hari pada ruas Sp .Jalan Elak-Jembatan Alue Awe volume terbesar diperoleh pada hari Rabu, yaitu $21466 \mathrm{kend} / \mathrm{jam}$ atau 10237,8 smp/jam. Namun demikian volume ini tidak terlalu besar perbedaannya dengan volume hari kerja berikutnya yaitu seperti pada hari kamis $15533 \mathrm{kend} / \mathrm{jam}$ atau 9514,9 smp/jam yang berarti volume rata-rata hari kerja sama. Dan dari penelitian ini terlihat bahwa volume hari libur rendah, sehingga tidak dapat digunakan untuk Volume Jam Perencanaan.

Berdasarkan hasil perhitungan kapasitas jalan diketahui kapasitas Sp .Jalan Elak-Jembatan Alue Awe adalah 2061,29 smp/jam. Dengan demikian kapasitas tersebut hasilnya lebih kecil dibandingkan dengan volume kenderaan maksimum pada setiap ruas jalan. Maka ruas jalan tersebut masih memadai untuk dilalui namun dengan kecepatan yang semakin terbatas atau menurun dan tingkat kenayaman yang mulai berkurang.

Data arus lau-lintas yang digunakan dalam penelitian ini adalah data yang diambil dari pengamatan langsung di lapangan yang bertujuan untuk mengetahui volume lalu-lintas berdasarkan dari jenis kenderaan. Sehubungan dengan masing-masing kenderaan memberikan pengaruh yang berbeda-beda dalam arus lalu-lintas, maka kenderaan dikelompokkan menjadi tiga tipe yaitu sepeda motor (MC), kenderaan ringan (LV) dan kenderaan berat (HV).

Berdasarkan hasil penelitian selama 3 hari diperoleh arus lalu-lintas harian rata-rata yang berbeda. Arus lalu-lintas terpadat terjadi pada hari Rabu dan 
berikutnya hari kamis, sedangkan hari Minggu (hari libur) rendah. Hal ini bermakna pada hari kerja banyak masyarakat yang melakukan aktifitas (berkerja, kuliah, berjualan dan lain-lain) sehingga lalu lintas yang memakai jalan menjadi semakin tinggi.

Hasil perhitungan kapasitas pada Sp.Jalan Elak-Jembatan Alue Awe berdasarkan LHR rata-rata selama 3 hari penelitian adalah sebesar 2061,29 smp/jam. Nilai tersebut lebih kecil dari nilai kapasitas dasar yang disarankan pada MKJI 1997 yaitu sebesar $2900 \mathrm{smp} / j a m$ untuk katagori jalan dua lajur tak terbagi. Hal ini disebabkan oleh beberapa faktor antara lain; faktor penyesuaian kapasitas akibat lebar lajur lalu-lintas, faktor penyesuaian kapasitas akibat pemisah arah, faktor penyesuaian kapasitas akibat hambatan samping dan faktor penyesuaian kapasitas akibat ukuran kota.

Dari perhitungan hambatan samping yang didapatkan berdasarkan 3 hari penelitian adalah adalah 68,59. Frekwensi berbobot kejadian di Sp .Jalan ElakJembatan Alue Awe tersebut termasuk dalam katagori tingkat hambatan samping sangat rendah (VL) dengan kondisi daerah permukiman penduduk dan beberapa toko disisi jalan. Hambatan samping berpengaruh terhadap kapasitas dan kinerja jalan antara lain: Pejalan kaki, angkutan umum dan kenderaan berhenti, kenderaan lambat (misalnya sepeda, becak) serta kenderaan masuk dan keluar dari lahan samping jalan. Kelas hambatan samping ini dibagi menjadi beberapa kelas yaitu sangat rendah (VL), rendah (L), sedang $(\mathrm{M})$, tinggi $(\mathrm{H})$ dan sangat tinggi $(\mathrm{VH})$.

Hasil dari perhitungan kecepatan arus bebas yang didapatkan berdasarkan penelitian selama 3 hari pada Sp .Jalan Elak-Jembatan Alue Awe dapat ditentukan berdasarkan rumus (5) dan grafik A.1 adalah $36 \mathrm{~km} / \mathrm{jam}$ (lihat lampiran A). Kecepatan arus bebas dasar yang disarankan MKJI 1997 untuk tipe jalan dua lajur dua arah tak terbagi ini adalah $\mathrm{FVo}=42 \mathrm{~km} / \mathrm{jam}$, untuk nilai faktor penyesuaian akibat lebar jalan adalah $\mathrm{FVw}=-3 \mathrm{~km} / \mathrm{jam}$ kemudian untuk nilai faktor penyesuaian akibat hambatan samping dan bahu jalan adalah FFVsf $=1,01$ untuk nilai faktor penyesuaian ukuran kota adalah $\mathrm{FCcs}=0,90$.

Dari hasil perhitungan Sp .Jalan Elak-Jembatan Alue Awe masuk dalam katagori tingkat pelayanan (LOS) $\mathrm{C}$ yang berarti arus lalu-lintasnya Arus stabil, kecepatan makin terbatas. Kecepatan yang diperoleh dari kecepatan arus bebas lebih kecil dari yang diberikan oleh tingkat pelayanan hal ini disebabkan oleh beberapa faktor di atas. Faktor-faktor tersebut dipengaruhi oleh situasi/keadaan pada jalan lokasi penelitian, yaitu seperti adanya gedung-gedung (bangunanbangunan). fasilitas umum, pertokoan dan lain-lain yang ada di kiri kanan jalan

Dari hasil perhitungan derajat kejenuhan yang didapatkan berdasarkan 3 hari penelitian adalah bervariasi mulai dari nilai 0,45, 0,42 dan 0,28. Setelah dirata-ratakan didapat derajat kejenuhan adalah 0,44 yang berarti termasuk dalam tingkat pelayanan $\mathrm{C}$, artinya arus stabil, kecepatan makin terbatas. Berdasarkan nilai yang disarankan MKJI 1997 derajat kejenuhan (DS) dengan tingkat pelayanan (LOS) dikelompokkan 6 kelompok. Untuk lebih jelas akan diperlihatkan di Tabel 7 di bawah in: 
Tabel 7 Hubungan tingkat pelayanan dengan derajat kejenuhan

\begin{tabular}{|c|c|l|}
\hline $\begin{array}{c}\text { Tingkat Pelayanan } \\
\text { (LOS) }\end{array}$ & $\begin{array}{c}\text { Derajat } \\
\text { Kejenuhan (Ds) }\end{array}$ & \multicolumn{1}{|c|}{ Keterangan } \\
\hline A & $0,0-0,2$ & Arus bebas, kecepatan bebas \\
\hline B & $0,0-0,4$ & Arus stabil, kecepatan mulai terbatas \\
\hline C & $0,4-0,6$ & $\begin{array}{l}\text { Arus stabil, kecepatan makin } \\
\text { terbatas }\end{array}$ \\
\hline D & $0,6-0,8$ & $\begin{array}{l}\text { Arus mulai tidak stabil, kecepatan } \\
\text { menurun }\end{array}$ \\
\hline E & $0,8-1,0$ & Arus tidak stabil, kecepatan rendah \\
\hline F & $\geq 1,0$ & Arus terhambat, kecepatan rendah \\
\hline
\end{tabular}

Sumber: MKJI 1997

Berdasarkan hasil tinjauan langsung di lapangan yang dilakukan selama 3 hari arus lalu lintas pada jalan tersebut terlihat mengalami kemacetan atau kecepatan menurun. Dari hasil penelitian menunjukkan jalan tersebut termasuk katagori LOS C yang artinya arus lalu-lintas stabil dan kecepatan makin menurun (terbatas). Hal ini berarti hasil penelitian bila dibandingkan dengan hasil pengamatan langsung di lapangn sudah mendekati. Sehingga telah cocok (layak) jika dilakukan pembangunan jalan dua jalur dua arah terbagi (dengan median).

\section{Kesimpulan}

Dari hasil penelitian dan pembahasan yang telah dilaksanakan, diperoleh kesimpulan sebagai berikut:

1. Besarnya nilai Lalu Lintas Harian Rata-rata (LHR) pada Simpng Jalan ElakJembatan Alu Awe (Jalan Banda Aceh- Medan) adalah hari Rabu 930,71 smp/jam, hari Kamis 865 smp/jam dan hari Minggu 578,02 smp/jam.

2. Hasil perhitungan derajat kejenuhan (DS) adalah 0,44 dengan tingkat pelayanan (LOS) adalah C, yaitu arus lalu-lintas stabil kecepatan makin terbatas (sudah kurang nyaman). Besarnya nilai ini (DS) sanagat dipengaruhi oleh kondisi pada sekitar wilayah keberadaan jalan tersebut.

3. Berdasarkan hasil tinjauan langsung di lapangan yang dilakukan selama 3 hari arus lalu lintas pada jalan tersebut terlihat mengalami kemacetan atau kecepatan menurun. Hasil penelitian menunjukkan arus lalu-lintas stabil dan kecepatan makin menurun (terbatas). Hal ini berarti hasil penelitian bila dibandingkan dengan hasil pengamatan langsung di lapangn sudah mendekati yang berarti juga jalan tersebut sudah cocok (layak) untuk dibangun jalan dua jalur dua rah terbagi (dengan median) sesuai dengan petunjuk dalam Manual Kapasitas Jalan Indonesia (MKJI 1997)

\section{Daftar Kepustakaan}

Anonim, 1997, Manual Kapasitas Jalan Indonesia (MKJI), Departemen Pekerjaan Umum, Dirjen Bina Marga, Jakarta. 
Alamsyah, A. Ansyori, 2008, Rekayasa Lalu-lintas, Edisi Revisi, UMM Pres, Universitas Muhammaddiyah Malang, Indonesia.

Morlok, Edward K, 1995, Pengantar Teknik dan perencanaan Transportasi, Erlangga, Bandung.

O Glesby H, Clarkson dan Hicks Gary, R., 1988, Teknik Jalan Raya, Edisi keempat, Erlangga, Jakarta.

Sukirman, S., 1994, Dasar-sadar Perencanaan Geometrik Jalan, Nova, Bandung.

Suryadharma H dan Susanto B, 1999, Rekayasa Jalan Raya, Universitas Atma Jaya, Yogyakarta.

Tamin, OZ., 2008, Perencanaan, Pemodelan dan Rekayasa Transportasi, ITB, Bandung.

Wesli, 2012, Kajian Mobilitas Penduduk Pada Sistem Tranportasi Darat Pasca Tsunami di Propinsi Aceh, Teras Jurnal Vol 2 No 4, Jurusan Teknik Sipil Universitas Malikussaleh, Lhokseumawe, hal 281-290 